\title{
CIVILIZATION AND THE PURSUIT OF KNOWLEDGE*
}

\author{
By SIR RICHARD GREGORY, Bt., F.R.S.
}

$S^{\mathrm{n}}$ INCE the annualm abrupt end by the imminence of war, it has been neither desirable nor possible to bring members together for another meeting of the usual kind in Great Britain or overseas. Even now, a year after the armistrice, conditions are such that accommodation for all the sections of the British Association and their members at Newcastle or Birmingham, where, but for the War, we should have met in 1940 and 1941, is impracticable, on account of the devastation which these cities have suffered from enemy action. Next year, however, the series of annual meetings which was begun in 1831, when the Association was founded, will be-resumed at Dundee, and the broken parts of the chain will again be linked together.

This year's assembly is, therefore, of a token character and is limited to a single day instead of the week usually occupied in the presentation of scientific papers and the delivery of addresses before the various sections. By the statutes of the Association it is laid down that an annual meeting shall be held, and that the president shall deliver an address at such a meeting during his year of office. For a number of reasons these two obligations could not be met during the period of the War, though I have been re-elected to the presidency every year since 1939, when this high honour was bestowed upon me.

The intervening years have, however, been very usefully employed in the preparation and presentation of reports by research committees appointed by the Council of the Association and by a number of public conferences on scientific subjects of wide interest. The conferences were organised, with the approval of the Council, by the Division for the Social and International Relations of Science, which was founded at the Cambridge meeting in 1938 with powers to arrange such meetings at times or places other than those of the normal annual meetings. Beginning with a conference on "Science and World Order", held in September 1941, and attended by ropresentatives of more than twenty of the United Nations, a number of other conferences were arranged, the last being on "Scientific Research and Industrial Planning", held in December 1945.

All these conferences were concerned with aspects of modern science in relation to the outlook and service of contributors to the advancement of natural knowledge and their contacts with problems of progressive human development. This is the cause to which my chief thoughts and work have been devoted for the past fifty years, and for the promotion of which the British Association has always stood. As it is the custom of presidents of the Association to deal in their annual addresses with subjects which have long occupied their close attention, I cannot do better than follow the usual practice, in this swan-song of retirement, by taking as my theme "Civilization and the.Pursuit of Knowledge".

* Presidential Address to the British Association for the Advancement of Science, delivered on July 20.

\section{The Dawn of Civilized Man}

The nature, origin and evolution of life, and the endeavours of man to understand it and the place in the universe of the world in which he lives and has his being, have been discussed on many occasions at meetings of the British Association. In his presidential address at the Dundee meeting in 1939, Sir Albert Seward used existing knowledge to reconstruct a view of plant life on an ancient land of which Scotland is now a remnant, and sixty million years before it was inhabited by man. Even this long period dwindles into insignificance in comparison with that of more than two thousand million years which have elapsed since the earth took geological form in the astronomical universe.

Organic life has existed upon the earth for about 1,200 million years, but Homo sapiens as a product of its evolution can be traced back to a stage of less than one hundred thousand years. An impressive illustration of this short period of human tenancy was given in an address by Prof. James Ritchie as president of the Section of Zoology at the Dundee meeting. Taking the twelve hours on the dial of a clock to represent the span of 1,200 million years, living organisms would cover the period from midnight to seven o'clock. From this hour until 11.15, fishes and amphibia, reptiles, birds and mammals would successively develop and predominate, with primitive man making his appearance at less than a minute before noon and our own species less than a second and a half ago. On this time-scale, the period from our Neolithic ancestors of about ten thousand years ago to the present epoch is represented by one-tenth of a second.

It is usual to date civilization from those times of the New Stone Age, when men began to cultivate food-crops, care for and breed domesticated animals, make polished flint implements, produce the potter's wheel and the plough in their simplest forms, use boats for movement on water, undertake spinning and mining, and provide by artificial means for the primary needs of communal life-food, shelter and clothing. There are still a few groups of human beings who have not advanced beyond these primitive conditions of life; but as they have not progressively improved these conditions, they cannot be said to be civilized in the sense in which the word is now understood.

\section{What is Civilization?}

What civilization actually means depends upon the values attached to thoughts and works by which man has separated himself from his purely animal ancestry. In Johnson's time, the word was used only in a civil or legal sense and not as a measure of material, moral or intellectual attainment. Each of these elements of development can be a dominant characteristic of a human society at a particular place or period; and when they are combined to reach a high standard for the general good, the best type of social organisation may be said to have been reached. 
If civilization is regarded as a formative process, then a new era began when Neolithic man became a tool-using animal, with the desire to acquire new knowledge and apply it to improve the mode of life of himself and his fellows. Its roots are in the human mind and its character is determined by the aptitude to accept ideas and give effect to them. The course of development of material resources, of morals and religion, of language and other means of emotional expression, differs in time and place, but the creative or receptive agent is always the human mind. Refinement of manners and customs is commonly associated with conventional class distinctions, but these characteristics cannot rightly be said. to provide essential standards of advance in civilization. A better measure is afforded by the proportion of the community who participate in the general welfare and appreciate the opportunities provided for their physical comfort and intellectual culture.

Civilization is thus a continuous process, which for the present purpose may be said to have begun with the art of agriculture in the Near East about ten thousand years ago, and at an early date to have reached Britain with the potter's art. The first steps in the working of metals, such as gold and copper, seem, however, to have been made in the Nubian region of north-east Africa. At one time, therefore, the negroid branch of the human race could be said to have been in the van of civilization both in its art and material culture. When given opportunities for development, coloured people have proved themselves just as capable of creative thought and efficient action as the white or other groups.

It is indeed unwarrantable to assume that any group of individuals or racial types are superior to others solely because they possess greater wealth or power. There are many types of civilization, but none provides standards of highest attainment in every field of human thought and endeavour. In the past, each has had its rise and fall, sometimes because of climatic or other natural changes, but more often through the use of superior military forces and the subsequent occupation and administration of the vanquished territory. They all belong to the panorama of structures of human societies and take their separate places in the continuous record of the world's history, beginning with the advent of the New Stone Age about ten thousand years ago.

\section{Inquiry and Interpretation}

In the study of man and his activities, three types of eultural development may be recognized; and they are all measured by different standards. In the fine arts the imaginative qualities of the mind appeal primarily to the emotions through stimulation of the æsthetic judgment, with feeling rather than reason as the standard of value; material culture is the province of mechanical arts; and science-the domain of reason-is systematic and formulated knowledge in all fields of human understandingnatural, moral, social and political. Natural science, or natural philosophy, is only one division of science as thus defined; yet, by general usage, the single word now signifies organised natural knowledge. The history of civilization from this point of view is a history of intellectual development in which science has been the chief factor in changing habits of thought from superficial observation and speculative and anthropomorphic theories of causation to clear concepts, rational conclusions, and progressive principles in the advancement of man and society.

In the most primitive times man had to acquire knowledge of the world of Nature around him in order to survive. The effort to secure the food and shelter necessary for his existence demanded a never-ceasing exploitation of the resources of his environment for the progressive improvement of his material equipment-an equipment which he learned to turn against his fellow man, no less than against the animal world upon which he preyed for food and clothing, or against which he must defend himself. But in this struggle, even more than on his personal prowess, his skill, and the bringing of food-plants and animals into his service, man relied upon his imagined understanding of, and his supposed power to control, the hidden causes of the nature and behaviour of the beings and objects of his world; in other words, he believed that natural conditions and events could be modified by the medicine of magic. Though the magical beliefs of primitive man may seem to us vain and crude, they should not be despised; for in these blind gropings to probe causation in Nature may be seen the remote and humble beginnings of the urge to the understanding of the universe, which is science.

When, however, magic is understood to be the practice of the pretended art of influencing the course of natural events by compelling the agency of spiritual beings, or by bringing occult principles into operation, it is more closely related to religion than to science. Art became associated with magic and religion many thousands of years before the era of the New Stone Age, which has been taken as the beginning of civilization of human societies. Thirty thousand years or so earlier, realistic paintings and drawings were made on the walls of dark caves, and objects were carved on bone and ivory, or fashioned in clay. They still remain to afford the earliest tangible evidence of that spirit in man's nature which was to act as his guide, both for good and ill, in his upward progress towards the most advanced stages of development to which civilization has yet attained.

There are several views as to the nature of the urge which led to these manifestations of early cultural development. One is that early man, like his counterpart, the backward peoples of modern times, believed that, by the exercise of his ability to represent his desires in graphic form--in other words, to effect his purpose of controlling those forms of animal life upon which he depended for his food-supply-he was setting in motion forces more potent than his own to that end, and making of his painting and carving an act of magical invocation, or it may be of religious observance.

Even if nothing more than a magical significance be attached to these realistic representations-cavebear, mammoth or bull, the browsing deer and the vital energy of a galloping herd of horses, and the like certain other examples of this artistic activity afford evidence of ideas which can be placed within the category of religion, if only of a rudimentary type. Some of the figures are forms of men with heads masked as animals, such as appear in representations of gods in aneient Egypt and Babylonia. They are regarded, therefore, as evidence of early conceptions of a spirit - even of a divinity-in animal form, and are associated with worship and supplication, whether for material desires or as ceremonial connected with a cult of the dead. 


\section{Worship and Works}

By Neolithic times our direct progenitors gave expression to certain clear conceptions of their belief in a form of existence after physical death and made provision for it in graves during the ritual of interment. Bodies were laid in particular positions with reference to the rising or the setting sun; and for the continued sustenance of the spirit, food was provided, with weapons for its protection, ornaments as amulets to ward off evil influences, and when human sacrifice was a part of the ritual, slaves to administer to its needs. Whatever the origin of these and other spiritual beliefs, the practice of them marks a distinct stage in the development of man's mind and works and has always played a potent part in shaping the structure of civilized life.

From one point of view, worship in the sense of adoration or reverence of the spirits of ancestors represents recognition of particular qualities of human nature and the desire to maintain them. When these qualities are conceived to be possessed supremely by supernatural beings, religion assumes a wider and more purposeful meaning. It becomes an attitude of mind towards the mysterious, with instinct as its basis and intuitive feeling as the standard of value. Religious experience can claim to be positive knowledge just as much as facts which appeal to the physical senses can be said to represent ultimate reality. As factors which have influenced human development throughout all stages of civilization, religion and science are inseparable, but it cannot be said that the two systems of thought have the same rates of rational advance, whether in principles or practice. Each is concerned with the pursuit of truth whether for its own sake or for increasing the contacts of human life with things and forces, visible and invisible, in the heavens and on the earth.

The light of truth is a spectrum of many colours to which human consciousness is receptive in varying degrees. In the physical sense, light does not become manifest until it is reflected by matter, and in the sense of a divine influence its truth has to be perceived spiritually. It is through the study of the heavens and the earth from these two points of view of worship and inquiry that religion and astronomy meet in celestial fields. All living things upon the earth depend upon the light of the sun for their origin and growth. Many millions of years before man appeared, there were song-birds which did homage to its power in pæans of thanksgiving at the passing of darkness and the coming of dawn. This form of salutation may be regarded as the beginning of instinctive reactions to the influence of light, which in man became worship and religious observance. With the recognition of the sun as a great power-station having a deity in charge came the association of light with life and goodness, and darkness with death and evil. Whether these higher abstract qualities attributed to celestial beings are reflexions of what are observed and admired in human communities or reactions to divine influence is a question which cannot be answered by positive knowledge, and must be left to individual consciousness for judgment.

\section{Celestial Movements and Meanings}

When the apparent movements of the sun and moon were used to measure intervals of time and seasons, the knowledge gained was intended for practical service and not as a contribution to rational or abstract truth. Astronomy was then the handmaid of astrology, which associated human lives and affairs with particular parts of the celestial sphere and the deities who occupied them. Astronomy is still the science of the heavenly bodies, but these are studied as physical objects and not as living beings. An immense amount of precise knowledge of celestial phenomena and events was obtained in ancient Egypt and Assyria, and its factual value is not affected by interpretations given to it. The accumulation and correlation of all such natural knowledge acquired by observation or practical experience is the function of science, while the way in which it is applied and interpreted affords a measure of the strength of a community in the history of civilization.

The association of astronomical objects and events with religious and other festivals, and with theological teaching, is a characteristic of most early civilizations, and is expressed in much of their art and literature. It is closely connected with the culture of Egypt and Mesopotamia, and also occupies a prominent place in the sacred literature of India. Among the material taken over by the Greeks from the Babylonians were the zodiac, knowledge of the planets and their courses among the constellations, and a method of predicting eclipses by means of the cycle known as the Saros-a period of eighteen years, eleven and one-third days. In this period, solar and lunar eclipses recur in a regular sequence at the same intervals of time and can, therefore, be predicted. Knowledge of the period descended to the Chaldeans, who occupied a part of Babylonia, and was transmitted by them to the Greek and Roman worlds.

When particular facts about phenomena or events reveal relationships from which no exceptions are known, they are expressed as scientific truths, and in this sense represent natural principles or laws. By discovering from the accumulation of observations during many centuries that 223 lunar months correspond with 18 years, $11 \frac{1}{3}$ days, or just over 6,585 days, the Chaldeans were able to announce the 'law of eclipses' as a natural and verifiable truth. This, like the regularity of the returns of the sun and moon and unchanging groups of stars, was a striking example of law and order in Nature, whatever views were held as to its cause or purpose in the scheme of human life.

Another cycle, not to be confused with the Saros, which relates only to the prediction of eclipses, was discovered in the fifth century B.c. by a Greek mathematician, Meton. $\mathrm{He}$ found that there was the same number of days, within a couple of hours, in 19 solar years as in 235 lunar months. This relationship was regarded as of such importance that it was inseribed in letters of gold from 1 to 19 on Greek monuments and was called the 'Golden Number'. For more than a thousand years the Metonic Cycle has been used to determine the date of Easter, upon which all the movable feasts of Christian Churches depend. As this date is determined also by that of the spring equinox, both the sun and the moon as seen from the earth are involved in it, but by the use of the simple cycle of Meton its prediction becomes relatively easy. The point of particular interest is that astronomical observations and measurements originated the dates of the chief religious festivals from the earliest civilized times to the present day. 
Reactions to influences of objects and phenomena of the heavens upon conditions of life on the earth thus connect both the physical and emotional parts of human nature. Interpretation of their causes depends upon the attitude assumed towards mysteries and the light of knowledge. Their creation and maintenance may be regarded as divine designs available for the service of mankind or as elements and forces in a universe in which the earth is but a particle. The view that celestial objects are the sources or symbols of the vital force or forces appears at the very dawn of civilization as the foundation of the great religions of the world. It was expressed in the faiths of Ancient Egypt and Assyria by impressive ceremonies in magnificent temples.

Knowledge of the constellations seems to have come to the Greeks through the Phœnicians, and was brought into practical service by its use in navigation. Homer refers to certain stars as having been sent by Zeus as portents for mariners. There are many other references to constellations in the Homeric epic poems, which describe conditions of life and thought in the period of the ninth and eighth centuries B.c. Hesiod, who succeeded Homer, gave more details of the guidance for farming operations afforded by the appearance of particular stars at different times of the year. He regarded the Iron Age, which was then beginning, as degenerate in comparison with the earlier Bronze and Stone Ages whon man lived in perfect innocence in a veritable Garden of Eden. The works of both Homer and Hesiod portray stages of civilization when the affairs of deities were believed to be much the same socially as those of human beings, with little difference in their qualities or actions. Heaven and earth were thus brought together in spiritual as well as practical service, and heroes became divinities in celestial abodes.

In the Indus valley civilization the Aryans, when they invaded the country not later than the middle of the second millennium B.C., brought with them concepts which personify the forces of Nature as divine and spiritual beings. Their attitude and outlook are embodied in the hymns of the "Rigveda", which date from about 1200 B.c. and were developed in the treatises known collectively as the "Upanishads", or conferences, in about the same period as that of early Greek philosophy. The belief in the personified natural forces of the Vedas was finally carried so far as the creation of an organised polytheism or pantheon and an elaborated caste system of society in which the Brahman was supreme instead of the warrior of the Vedic classics.

\section{Natural Knowledge and Philosophy}

In this early philosophy, man is the centre of the cosmic scheme, and he shares the vital force with the gods, without being dependent upon them. He differs from all other things, animate or inanimate, in the capacity for thinking, leading eventually to the Brahmans becoming the 'head' of the social organism because they possessed it to a higher degree than other classes, including the warriors, whose powers depended upon the use of 'lower' parts of the human body. Brahmanism became a new Hinduism with the teaching that every Hindu could share this knowledge and by mystical thought attain to the same perfection. Many variations of these beliefs have been formulated and incorporated in Hinduism, but the main ideas remain the same. With the introduction of Buddhism in the sixth century B.c., came the teaching that the performance of sacrifices and daily rites to deities were no measure of attainment of the right way of human life and conduct. Since that time Hinduism and Buddhism, together and separately, have determined the course of eivilization in the Middle and Far East.

It is a remarkable historical fact that the sixth century B.c. was a period of great emotional and intellectual ferment, in which there was displayed a general and widespread interest in religious and philosophic speculation, particularly in the East. Buddhism, Taoism, and Confucianism all had their origin in that century; and their followers to-day number more than half the population of the world. There is no personal god in these religions or ethical systems; but conceptions of relationships between the heavens and the earth, or the universe and man, are common components of them. Each is concerned with a way of life and the exercise of human virtues, and each is tolerant of the others. It is thus possible for the three cults, with Christianity in addition, to be accepted together as guides to individual conduct, without discrimination between them.

Though there are decided differences between the principles of Taoism and those of Confucianism, each system makes ethical conduct its chief object, and neither is associated with fanaticism against other religions. The cult of ancestor worship in China has no mythological motive, but expresses the philosophical conception that continuation of life lies not in the immortality of the soul, but in the perpetual remembrance of the righteous by mankind. The original teaching of Taoism has, however, been modified by contact with Buddhism, and Lao-tze, its founder, has become one of a trinity of deities in a mystical pantheon. While it is possible to say simply of Buddhism that it was concerned with the way of salvation of the individual, Confucianism, which is synonymous with Chinese civilization, aimed at the regeneration of a whole society through a reformation in the conduct and character of all its members.

Just as in the sixth century B.C., Buddhism, Taoism and Confucianism separated man from celestial deities, so in the same period the Greek philosophers Thales and Pythagoras began the study of Nature as made manifest to the senses with the view of discovering relationships between effects and causes. They and their Ionian school were the first 'lovers of wisdom' to separate natural philosophy from all-personifying religious faith and to constitute a method of interpreting Nature distinct from the primitive conceptions of unenlightened minds. The idea of Person in a divine sense was tacitly set aside or limited, and an impersonal Nature conceived as a separate subject of study. The scope of natural philosophy, with its objective character and invariable laws, discoverable by a proper and methodical application of the human intellect, was thus defined. Though these principles were not maintained for long, they opened up those veins of speculative philosophy which oceupied afterwards so large a portion of Greek intellectual energy, with most enduring results on Western civilization.

Plato, the greatest of these thinkers, opposed the scientific school which had arisen to study natural objects and phenomena apart from supernatural agencies, and to interpret the processes involved by submitting them to independent rational inquiry. It was against these materialists, of whom Democritus of the fifth and fourth centuries B.C. was the leader and last of the physical school, that the main argu- 
ments were advanced by the Socratic system of reasoning in the tenth book of Plato's "Laws". Disregard of the gods, or unbelief in their concern for human affairs and conditions affecting them, was held to be a danger to a State and a crime to be denounced by every law-abiding citizen and punished severely.

The words used by Plato near the beginning of the discourse express very clearly the difference between the scientific and theological attitudes towards the pursuit of natural knowledge; and they are to-day as truly typical of the two points of view as they were in the first recorded statement of conflict between religion and science.

"It is the novel view of our modern scientists," said Plato, "that we must hold responsible as the cause of mischief. For the result of the arguments of such people is this; that when you and I try to prove the existence of the gods by pointing to these very objects-Sun, Moon, Stars and Earth-as instances of deity and divinity, people who have been converted by these scientists will assert that these things are simply earth and stone, incapable of paying any heed to human affairs, and that these beliefs of ours are speciously tricked out with arguments to make them plausible."

This denunciation of the mode and meaning of the studies of the early Greek physicists has particular interest at the present time: for it was directed against Democritus, the renowned founder of the atomic theory. It is a tribute to the free intellectual atmosphere of Greece at the time that such an impious theory should have been conceived at all. In its crude form, the Athenian, Epicurus, used the theory as the basis of ethical teaching in which divine providence had no part; and it was expounded by Lucretius to the Roman world in his comprehensive philosophical poem "On the Nature of Things".

\section{The Disruptive Atom}

Lucretius' fervid exposition of the theory that the universe may be analysed into two elements-atoms and space--in different relationships even as an explanation of life, the mind and the soul, makes his poem a great contribution to the philosophy of science as well as to classical literature. According to this view, all forms of matter are due to combinations of unalterable atoms in ceaseless motion; and the universe is a vast concourse of them under the control of fixed laws and independent in these respects of a providence or intelligent cause continually guiding their movements.

The theory remained a philosophic speculation for about eighteen centuries before attention to it was revived; and it was established as the foundation of modern chemistry by John Dalton early in the nineteenth century. Towards the end of that century, the discovery was made that the chemical element, uranium, continuously emitted radiations which produced effects of both heat and light without measurable loss of mass. This led to the discovery of radium and other radioactive substances; and scientific attention was concentrated on all their aspects-theoretical and applied.

At the beginning of the present century these studies led to the conclusion that the energy released by radioactive action was due to the spontaneous disintegration of their constituents. In the terminology of chemistry, atoms are still the smallest units which enter into combination; and they make up the constitution of all substances, just as millions of aurerent words are formed from letters of the alphabet. Chemical atoms are, however, now known to consist of systems of smaller particles in very rapid motion around a nucleus; and their physical disruptions become manifest in the effects of radioactivity. The source of this energy was proved later to be in the nucleus of the atom and not in the lighter particles called electrons, revolving around it. Further experiments showed that the core itself could be divided and that the process was sometimes accompanied by an enormous output of energy.

These principles of nuclear fission had been established before the discovery was made, early in the year 1939, that when the nucleus of an atom of uranium had been split in two, additional atomic bullets were produced which carried on the disintegration process by themselves. A chain reaction could thus be created which broke up the uranium with great rapidity and at the same time released energy with immense violence.

All this experimental work was done purely in the pursuit of natural knowledge, and was communicated freely to scientific societies and publications. The military significance of the fission chain reaction then came to be realized both in Europe and the United States, where, with the collaboration of American, Canadian and British scientists, a vast engineering plant was erected, and the frightful atom bomb was manufactured as an instrument of war. There were no secrets in the principles upon which its construction was based, but, as with other industrial applications of scientific discoveries, the conversion of laboratory experiments into engineering works on a vast scale meant that special methods had to be discovered and used in the process, and these alone constitute the secrets of atom bomb manufacture.

British and American scientists and technologists took three years to convert laboratory experiments into an engineering plant, that is, to bridge the gap between science and invention, and by so doing to make available an almost inexhaustible source of mechanical power. When atoms took form out of the void, this energy was locked up in their nuclear hearts; and whatever may be the spiritual meaning or purpose of its creation, the discovery of it in the pursuit of knowledge is just as natural as that of any other force. When Prometheus of classical antiquity stole fire from heaven for use on the earth, he was condemned by Zeus to daily torture for this sacrilege. The celestial fire stored up by plant cells many millions of years ago and concentrated in sediments of the earth's crust is stolen daily in the form of coal and oil and used for the service of man.

The view that to acquire such knowledge of natural properties and forces is to partake of its divinely forbidden fruits is still held and has been forcibly expressed against scientists since atom bombs were exploded with such terrible effects over Hiroshima and Nagasaki. There can never be moral sanction for such mass destruction of human life, though history affords other examples of it in crusades and similar religious conflicts. It is an offence against the light, for whatever cause it is undertaken. The pursuit of natural or of supernatural truth is the noblest of man's endeavours. The use of the knowledge gained has enabled man to penetrate into the centres of stars, but it can carry him also down into the pit to perish if his animal instincts continue to prevail over his moral understanding.

( $T$ o be continued) 